\title{
Catalizadores para la producción de plastificantes derivados de la biomasa
}

\section{Catalysts for the production of plasticizers derived from biomass}

\section{Doctorando:}

\author{
Federico Aguzín \\ Centro de Investigación en Nanociencia y Nanotecnología (NANOTEC) \\ fedeaguzin@gmail.com
}

Director/es:

Dra. Nora Okulik, Dra. Cristina Padró y Dra. Andrea Beltramone.

\begin{abstract}
Resumen
El uso de la biomasa como materia prima para la síntesis de diversos materiales es una actividad que continúa creciendo y ha permitido el desarrollo de nuevos procesos y productos, como la síntesis de bioplastificantes a base de ácidos orgánicos como el ácido succínico, y materiales carbonáceos a partir de azúcares, polímeros naturales como la celulosa, almidón, entre otros. Aquí hemos desarrollado una serie de catalizadores, entre ellos uno a base de almidón con propiedades ácidas, un material mesoporoso no cristalino como la SBA- 15 con $\mathrm{ZrO}_{2}$ incorporado y sulfatada, y carbones impregnados con ácido dodecatungstofosfórico. Estos fueron probados en la reacción de esterificación de ácido succínico con etanol, empleando la resina ácida Amberlyst 36 como catalizador de referencia para comparar los catalizadores y estudiar la influencia de los parámetros de reacción.
\end{abstract}

Palabras claves: Bioplastificante, Ácido succínico, Biomasa, Esterificación, Catálisis.

\begin{abstract}
The use of biomass as a raw material for the synthesis of various materials is an activity that continues to grow and has allowed the development of new processes and products, such as the synthesis of bioplastifiers based on organic acids such as succinic acid, and carbonaceous materials from sugars, natural polymers such as cellulose, starch, among others. Here we have developed a series of catalysts, including one based on starch with acidic properties, a noncrystalline mesoporous material such as SBA-15 with $\mathrm{ZrO}_{2}$ incorporated and sulfated, and carbons impregnated with dodecatungstophosphoric acid. These were tested in the esterification reaction of succinic acid with ethanol, using the Amberlyst 36 acid resin as a reference catalyst to compare the catalysts and study the influence of the reaction parameters.
\end{abstract}

Keywords: Bioplasticizers, Succinic Acid, Biomass, Esterification, Catalysis.

\section{Introducción}

Los plastificantes son sustancias que, incorporadas a un material, como un plástico o un elastómero, permiten mejorar su flexibilidad, manejabilidad o dilatabilidad (IUPAC); se añaden en una proporción que puede llegar hasta el $40 \%$ [1]. Se espera que el mercado de plastificantes alcance un volumen de consumo de unos 10,5 millones de toneladas/año para el 2026, año en el que los plastificantes libres de ftalatos tendrán una tasa de crecimiento de unos 2,3 millones de toneladas/año, es decir, un $22 \%$ [2]. 
Existen restricciones en el uso de plastificantes a base de ftalatos debido a sus efectos tóxicos, particularmente del DEHP (di-2-etilhexilftalato) que es el más usado [3] lo que ha conducido a la necesidad de reemplazarlos estimulando el interés por la investigación y desarrollo de "plastificantes verdes" [4]. En la búsqueda de sustitutos del DEHP, mostraron ser compatibles con el PVC [5] diversos ésteres basados en ácidos carboxílicos (succínico y cítrico). Así, la producción de ésteres plastificantes a partir de ácidos y alcoholes provenientes de procesos de fermentación, u otras rutas bio-derivadas, se convierte en una oportunidad para reemplazar los plastificantes de origen petroquímico abriendo nuevos mercados a los productos de la industria química nacional. En Argentina la demanda anual de plastificantes para caucho o plásticos es de 355 toneladas (promedio 2012-2014), mientras que las exportaciones ascienden, en promedio, a 20.000 toneladas para el mismo período. En el proceso de identificación de oportunidades para la sustitución de importaciones se presentó el proyecto vinculado a la fabricación de plastificantes de origen vegetal, que actualmente son demandados por de la UE (Plan Estratégico Industrial 2020), por lo que puede decirse que el futuro de los plastificantes de origen vegetal reside en la agricultura.

\section{Objetivo general}

Desarrollar procesos catalíticos eficientes utilizando productos provenientes de residuos de biomasa utilizando una alternativa técnica y económicamente viable para el mercado local. Específicamente el interés está centrado en el desarrollo de reacciones que conduzcan a la producción de compuestos básicos para la elaboración de plastificantes a partir de materia prima renovable y que reemplacen a los tóxicos producidos a base de ftalatos.

Objetivos específicos

A) Desarrollar nuevos materiales sólidos porosos que sean activos en la reacción de esterificación de compuestos típicos provenientes de la fermentación de biomasa (ácido cítrico y ácido succínico) con alcoholes de C2 a C6. Este objetivo comprende la síntesis de sólidos mesoporosos carbonáceos (derivados de polisacáridos) y zeolíticos laminados o pilarizados; la funcionalización de los materiales no ácidos y la caracterización fisicoquímica y de la acidez de los catalizadores preparados.

B) Obtener ésteres de los ácidos succínico y cítrico con elevados rendimientos utilizando los catalizadores sólidos ácidos sintetizados. Se compararán los rendimientos alcanzados con los catalizadores preparados con los informados previamente u obtenidos utilizando catalizadores líquidos como ácido sulfúrico. Se seleccionará el catalizador más eficiente investigando el efecto de las propiedades ácidas y estructurales del sólido. Un punto importante en la selección del catalizador es la estabilidad y posible reutilización del mismo.

C) Lograr altos rendimientos en las reacciones de esterificación de los ácidos carboxílicos de origen vegetal con alcoholes utilizando la menor relación ácido/alcohol posible, bajas temperaturas y alta reusabilidad del catalizador.

Se desarrollaron una serie de materiales con el objeto de emplearlos como catalizadores en la reacción de esterificación del ácido succínico con etanol. Entre estos materiales están unos carbones basados en biomasa, como los carbones tipo Starbon a partir de almidón de maíz. También se practicaron impregnaciones sobre estos materiales al igual que otros comerciales, como carbón activado (CABOT®). También se logró sintetizar SBA-15 a la cual se le incorporó $\mathrm{ZrO}_{2}$.

\section{Resultados}

Síntesis de carbones ácidos mesoporosos tipo Starbon:

De acuerdo con el procedimiento descrito por Budarin [6] se llevó a cabo la síntesis de un material carbonoso a base de almidón de maíz. Para ello 20 g de almidón de maíz se mezclaron con $200 \mathrm{ml}$ de agua destilada por 15 minutos en un reactor de acero inoxidable cerrado y con calentamiento de $25^{\circ} \mathrm{C}$ a $120^{\circ} \mathrm{C}$ a razón de $1{ }^{\circ} \mathrm{C} / \mathrm{min}$, manteniendo la agitación del mismo. Tras este proceso el almidón expandido se extrajo por presión autógena del sistema y se llevó a heladera a $5{ }^{\circ} \mathrm{C}$ por 3 días para favorecer la retrogradación del almidón. El gel formado se trató con volúmenes de concentración creciente de etanol hasta una adición del 50 \%v. Seguido se filtró y se repitió el procedimiento hasta una concentración de adición del 95 \%. Se procedió de igual forma para intercambiar el etanol retenido en los poros usando acetona. Tras el intercambio con acetona se obtuvo un material blanco liviano y pulverulento, el cual se sometió a secado en vacío a $40^{\circ} \mathrm{C}$. Luego el almidón expandido y seco se impregnó con una solución de ácido p-toluen sulfónico al $3 \%$ disuelto en acetona. Nuevamente se sometió a secado en vacío a $40^{\circ} \mathrm{C}$. Finalmente se llevó a cabo la pirólisis del material impregnado y seco a $300{ }^{\circ} \mathrm{C}$ con una velocidad de calentamiento de $25{ }^{\circ} \mathrm{C} / \mathrm{h}$. Tras esta etapa se obtuvo un material marrón oscuro y pulverulento. Se practicó otra síntesis con una impregnación de ácido p-toluen sulfónico al 7 \%. Los materiales así obtenidos se denominaron C-3 y C-7.

Impregnaciones de HPA sobre carbón activado:

Se empleó como heteropoliácido (HPA) el ácido dodecatungstofosfórico $\left(\mathrm{H}_{3} \mathrm{PW}_{12} \mathrm{O}_{40} \cdot \mathrm{xH}_{2} \mathrm{O}\right)$. Se practicaron dos métodos de impregnación, uno descrito por Zuguang [7] en la que solo se emplea agua como solvente de impregnación, y otra descrita por Chimienti [8] en la que se emplea una solución etanol-agua como solvente de impregnación. Previo 
a cada impregnación el carbón activado fue pretratado por lavado en solución de $\mathrm{NaOH}$ 0,1 N, seguido de un lavado en $\mathrm{HCl} \mathrm{0,1} \mathrm{N.} \mathrm{Finalmente} \mathrm{se} \mathrm{trata} \mathrm{en} \mathrm{HNO}_{3} 30 \% \mathrm{p} / \mathrm{v}$ con reflujo por 2 horas; luego se filtra y lava varias veces.

Método 1: se mezclan $4 \mathrm{~g}$ de CA con $2 \mathrm{~g}$ de HPA disueltos en agua en un balón de vidrio a $100^{\circ} \mathrm{C}$ por 5 horas. Luego el material es filtrado y enjuagado con pequeños volúmenes de agua. El volumen total filtrado se almacenó para su posterior análisis en un espectrofotómetro UV-visible para determinar el contenido de HPA en solución y por ende la cantidad del mismo impregnada en el CA. Tras el filtrado el material se secó a $100^{\circ} \mathrm{C}$ en estufa.

Método 2: se mezclan $4 \mathrm{~g}$ de CA con $2 \mathrm{~g}$ de HPA disueltos en una solución etanol:agua al $50 \%$ dentro de un balón de vidrio y calentado a $100^{\circ} \mathrm{C}$ por 5 horas. Luego el material es filtrado y lavado como en el método 1, determinándose de igual forma el contenido de HPA. El material también es secado en estufa a $100^{\circ} \mathrm{C}$.

Determinación del contenido de HPA en solución:

Haciendo uso de un espectrofotómetro UV-visible automático marca Shimadzu modelo UV-1800, se midió la absorbancia de las muestras a $253 \mathrm{~nm}$ y se halló su concentración de acuerdo a la calibración hecha del analito. Luego se calculó la carga de HPA sobre el CA de acuerdo a:

$$
\text { Cantidad cargada de HPA }=\frac{\left(m_{\text {total }}-m_{\text {filtrado }}\right)}{m_{c}} \cdot 100 \%
$$

Donde, $m_{\text {total }}$ es la masa total de HPA en el sistema de impregnación, $m_{\text {filtrado }}$ es la masa de HPA en la solución de filtrado, y $m_{c}$ es la masa de CA cargado al sistema de impregnación.

Síntesis de SBA-15 con incorporación de $\mathrm{ZrO}_{2}$

El silicato mesoporoso SBA-15 fue preparado de acuerdo a Valles et al. [9]. Para ello se empleó tetraetilortosilicato (TEOS, 98\%, Sigma) como fuente de silicio. El agente plantilla Pluoronic 123 (P123) se disolvió en una solución de HCl $2 \mathrm{M}$ y el sistema se llevó a $35^{\circ} \mathrm{C}$, luego se añadió el TEOS al sistema bajo agitación. Seguido se mantuvo el sistema en condiciones estáticas por $24 \mathrm{~h}$ y posteriormente se transfirió a un recipiente de teflón manteniéndose en este a $80^{\circ} \mathrm{C}$ por $48 \mathrm{~h}$. Luego se filtró, se lavó con agua desionizada y se secó en estufa a $50^{\circ} \mathrm{C}$. El material seco se calcinó a $550^{\circ} \mathrm{C}$ por $5 \mathrm{~h}$ para obtener la SBA-15. El material se sometió a una impregnación húmeda con oxicloruro de circonio hidratado $\left(\mathrm{Cl}_{2} \mathrm{OZr} \cdot \mathrm{xH}_{2} \mathrm{O}\right)$. La relación molar teórica fue de $\mathrm{Si} / \mathrm{Zr}=20$. El material impregnado fue luego sulfatado con $\mathrm{H}_{2} \mathrm{SO}_{4}$.

\section{Caracterizaciones:}

Las caracterizaciones desarrolladas consistieron de la determinación de número total de sitios ácidos (NTSA) por titulación potenciométrica, fisisorción de nitrógeno a $77 \mathrm{~K}$ para la determinación de las características superficiales, también se tomaron imágenes SEM de algunos materiales. En la Tabla 1 se resumen los resultados de las caracterizaciones realizadas hasta el momento.

Tabla 1. Características de los catalizadores

\begin{tabular}{ccccc}
\hline Catalizador & $\begin{array}{c}\text { NTSA } \\
(\mathrm{mmol} \mathrm{H} / \text { gcat })\end{array}$ & $\begin{array}{c}\text { SBET } \\
\left(\mathrm{m}^{2} / \mathrm{g}\right)\end{array}$ & $\begin{array}{c}\mathrm{Vp} \\
\left(\mathrm{cm}^{3} / \mathrm{g}\right)\end{array}$ & $\begin{array}{c}\mathrm{Dp} \\
(\mathrm{nm})\end{array}$ \\
\hline $\mathrm{A} 36$ & 3.30 & $33^{\dagger}$ & $0.20^{\dagger}$ & $24^{\dagger}$ \\
$\mathrm{C}-3$ & 2.51 & 80 & 0.18 & 13 \\
$\mathrm{C}-7$ & 1.82 & 20 & 0.4 & 15 \\
$\mathrm{ZrO}_{2}$-SBA-15-H & 1.40 & 252 & 0.55 & 8.4 \\
$\mathrm{CA}$ & 0.62 & 776 & 0.25 & 4.3 \\
$\mathrm{HPA}$ & 6.01 & - & - & - \\
$\mathrm{HPA} / \mathrm{CA}-10 \%$ & 1.10 & 634 & 0.21 & 4.6 \\
$\mathrm{HPA} / \mathrm{CA}-20 \%$ & 1.12 & 507 & 0.18 & 4.3 \\
\hline
\end{tabular}

${ }^{\dagger}$ Datos suministrados por el proveedor

De los resultados de fisisorsión mostrados en la Tabla 1 puede apreciarse que la superficie del material tras la pirólisis disminuye al aumentar la carga de ácido p-toluen sulfónico sobre el almidón expandido. Esto podría deberse a que una cantidad superior del catalizador ácido provocaría una deshidratación más rápida durante la pirolisis provocando el colapso de la estructura porosa del almidón expandido seco.

La Fig. 1A muestra la isoterma de adsorción-desorción de Nitrógeno de tipo IV con lazo de histéresis tipo H1 correspondiente al $\mathrm{ZrO}_{2}$-SBA-15-H (materiales mesoporosos con poros de tamaño y forma uniforme), y la Fig. 1B muestra las isotermas de adsorción de
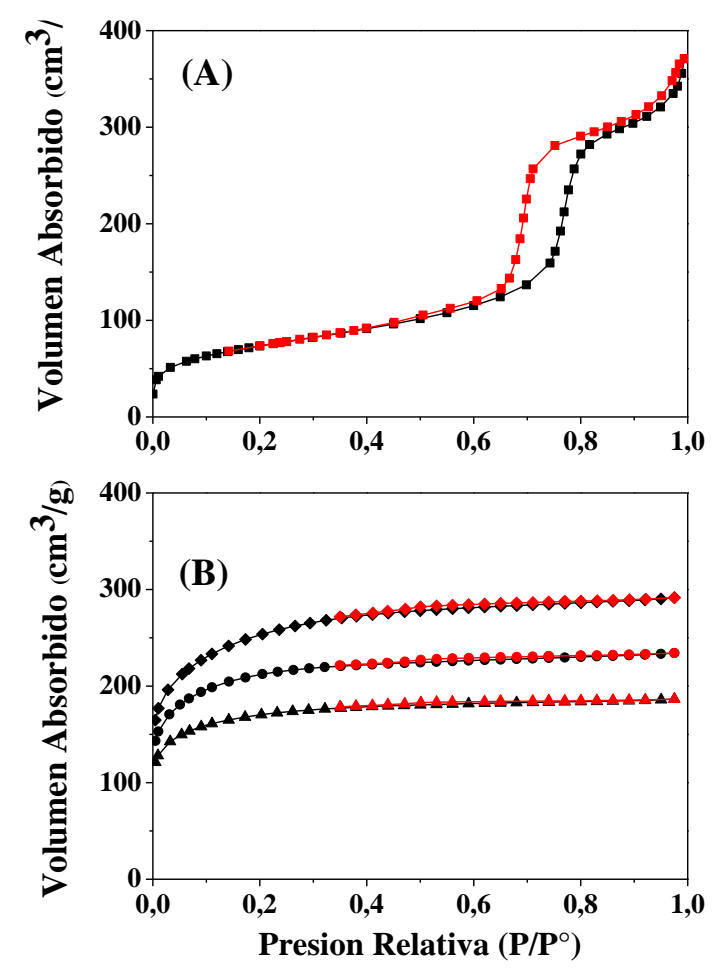

Fig. 1. Isotermas de adsorción y desorción de Nitrógeno de $\mathrm{ZrO}_{2}-\mathrm{SBA}-15-\mathrm{H}$ (A) y de CA $\diamond$, HPA/CA-10\% O y HPA/CA-20\% $\Delta \Delta$ (B). 
tipo IV de los carbones activados con lazo de histéresis tipo $\mathrm{H} 4$, (característicos de los carbones activados en el rango de los microporosos). La incorporación de HPA en los carbones provoca una disminución en el volumen total de poros y la superficie específica del carbón, aunque no se observa un cambio notable en el diámetro de poro medio.

La imagen SEM (Fig. 2A) del carbón sintetizado a partir de almidón con una impregnación de 3 \% de ácido ptoluensulfónico muestra un material con superficie aparentemente más rugosa que la del carbón desarrollado con 7 $\%$ de ácido p-toluensulfónico, esto se condice con los valores de superficie BET. En la Fig. 2C puede verse el material previo a la pirólisis, el cual exhibe superficies más lisas, con lo cual puede inferirse que la pirolisis permite el desarrollo poroso en el material.
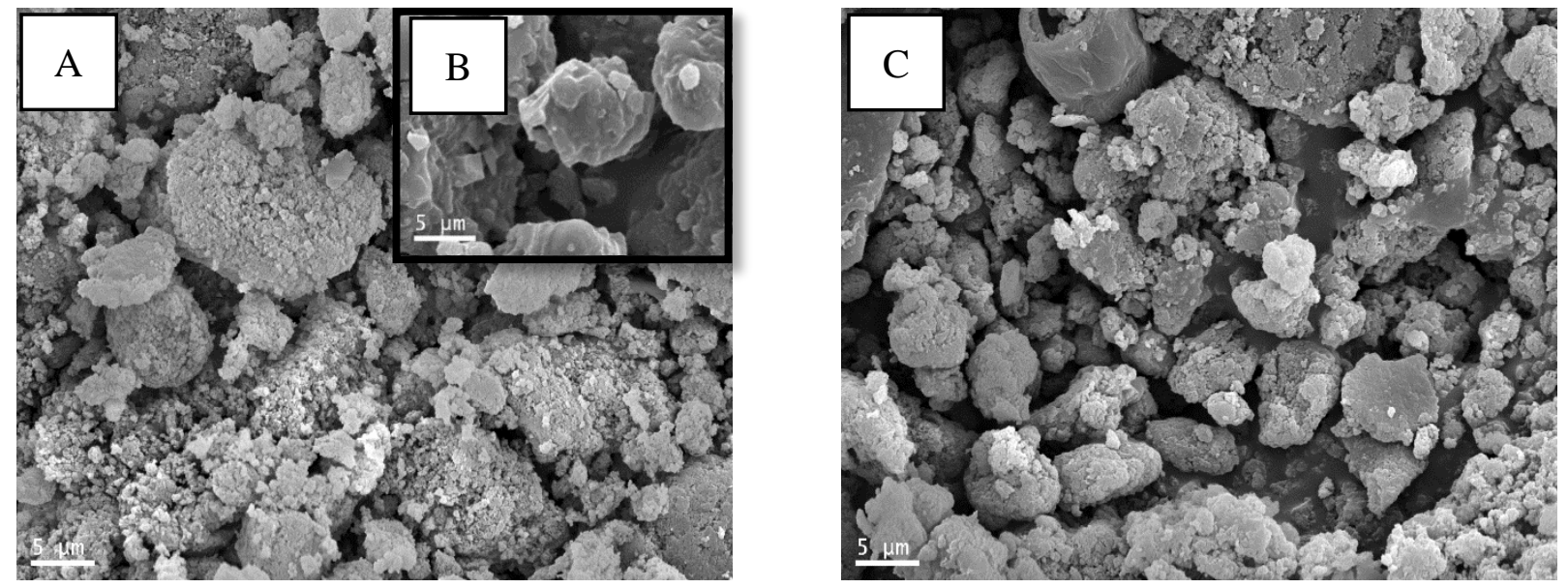

Fig. 1. Imágenes SEM de los carbones C-3 (a) y C-3 sin calcinar (b), y (c) C-7.

Resultados de actividad catalítica:

Los materiales preparados se probaron en las reacciones de esterificación del ácido succínico con etanol (Fig. 3).<smiles>O=C(O)CCC(=O)O</smiles>

Ácido succínico (AS)

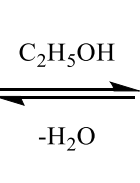

ción.

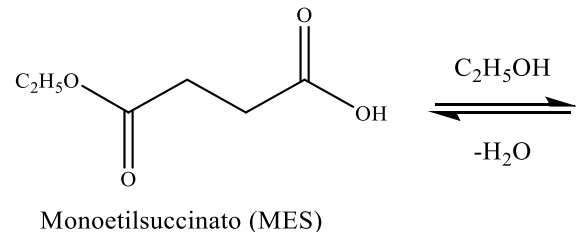

Monoetilsuccinato (MES)

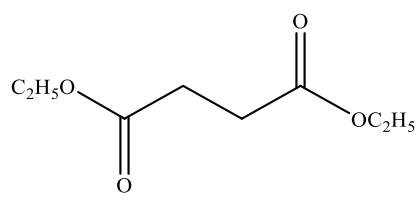

Dietilsuccinato (DES)

Influencia de parámetros de reacción.

Utilizando la resina A36 como catalizador se analizó la influencia de la temperatura, relación molar de reactivos y velocidad de agitación con el objetivo de seleccionar las condiciones que favorezcan un elevado rendimiento hacia el compuesto deseado (DES).

Realizando experiencias catalíticas variando las relaciones molares (RM=ácido/etanol) desde 1:10 hasta 1:40, la velocidad de agitación entre 600 y $1000 \mathrm{rpm}$ y la temperatura entre $80{ }^{\circ} \mathrm{C}$ y $120{ }^{\circ} \mathrm{C}$ de manera independiente, se determinaron los parámetros óptimos para cada reacción, que luego serán utilizados para comparar los catalizadores preparados. En la Fig. 4A se observa que la conversión y la selectividad no varían de forma apreciable con la velocidad de agitación, por lo que se opta por 800 rpm como el valor más favorable para evitar problemas difusionales. En la Fig. 3B las curvas correspondientes a las cargas de 1.0 y $1.5 \%$ p denotan diferencias mínimas de conversión (probablemente por saturación del catalizador), pero mucho mayores respecto al valor de $0.5 \%$ p. Respecto a la selectividad la diferencia es más notable entre la carga de 0.5 y $1.0 \%$ p, pero menor entre la carga de 1.0 y $1,5 \%$ p, por tanto, se optó por una carga de catalizador de $1.0 \%$ p. La influencia de la temperatura sobre la reacción se presenta en la Fig. $3 \mathrm{C}$ con un marcado aumento en la conversión al aumentar la temperatura de 80 a $100^{\circ} \mathrm{C}$, pero con mucha menor diferencia al variar de 100 a $110^{\circ} \mathrm{C}$; por su parte la selectividad aumenta de forma considerable con las temperaturas de 100 y $110^{\circ} \mathrm{C}$ respecto a la de $80^{\circ} \mathrm{C}$. Puesto que la resina $\mathrm{A} 36$ no es estable a temperaturas superiores a $110^{\circ} \mathrm{C}$, se consideró el uso de una temperatura de $100^{\circ} \mathrm{C}$ para extender la vida útil de la misma. La Fig. 3D muestra reducida variación en la conversión al variar la proporción de los reactivos; esta leve influencia sobre la reacción se evidencia más con las selectividades y se eligió el valor intermedio de este parámetro. 

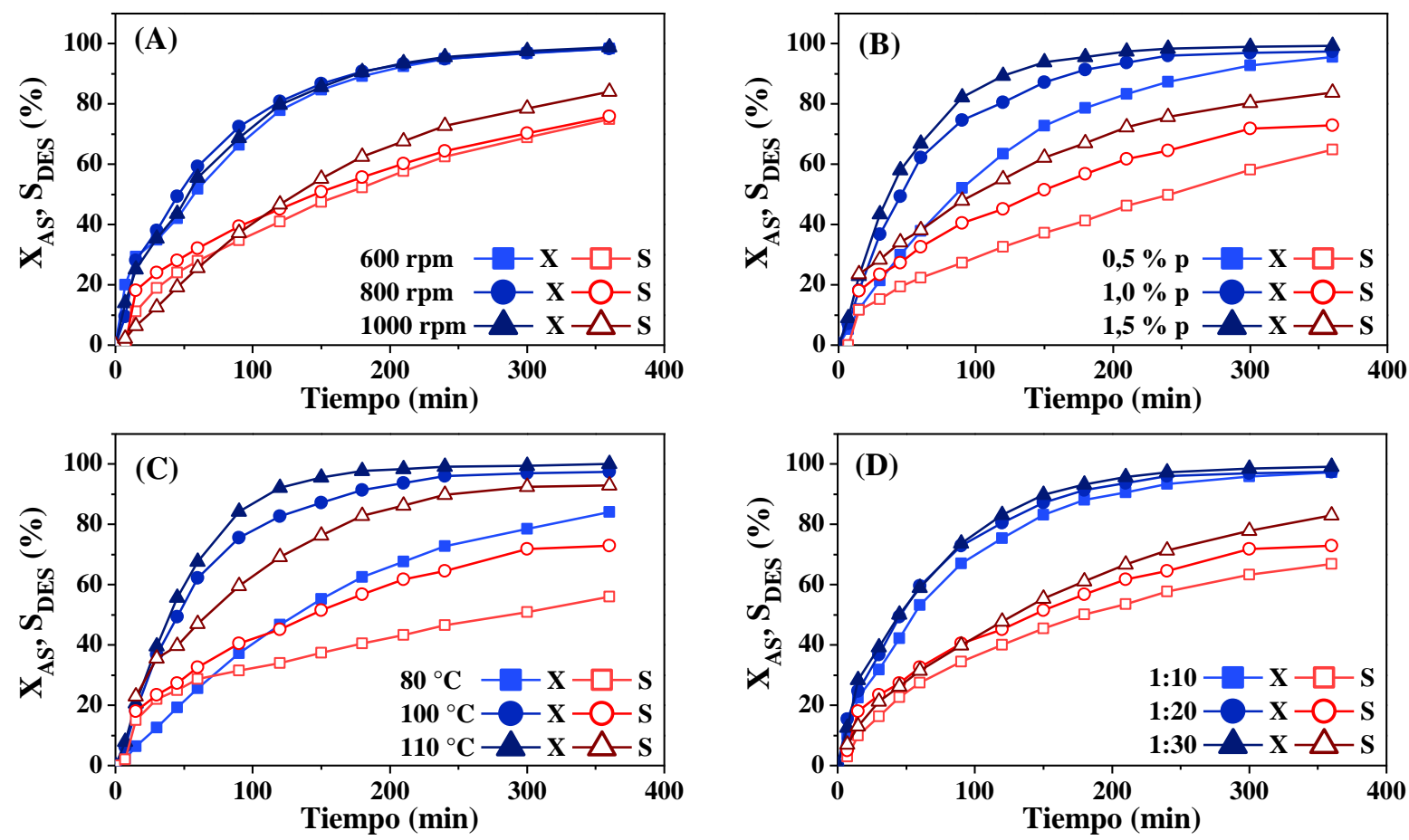

Fig. 4. Evaluación de la influencia sobre la conversión de AS y la selectividad hacia DES de: (A) velocidad de agitación [1 \%p cat., $100{ }^{\circ} \mathrm{C}$, AS:EtOH 1:20]. (B) carga de catalizador [800 rpm, $100^{\circ} \mathrm{C}, \mathrm{AS}:$ EtOH 1:20]. (C) Temperatura [1 \%p cat., 800 rpm, AS:EtOH 1:20]. (D) Relación molar [1 \%p cat., 100 C, 800 rpm, AS:EtOH 1:20].

Actividad catalítica de los catalizadores sintetizados:

En la Fig. 5 se muestra la conversión del AS (5A), la selectividad hacia el MES (5B) y la selectividad hacia el DES (5C); todas ellas evaluadas a $100{ }^{\circ} \mathrm{C}, 800 \mathrm{rpm}, 1 \%$ cat. y una relación molar 1:20 (AS:EtOH). De la Fig. 5A se puede apreciar que la conversión disminuye en el orden siguiente:

$$
\mathrm{ZrO}_{2}-\mathrm{SBA}-15-\mathrm{H}>\mathrm{HPA}>\mathrm{A} 36>\mathrm{C}-3>\mathrm{C}-7>\mathrm{HPA} / \mathrm{CA}-20 \%>\mathrm{HPA} / \mathrm{CA}-10 \%>\mathrm{CA}
$$

El superlativo comportamiento de $\mathrm{ZrO}_{2}$-SBA-15-H podría explicarse por el efecto sinérgico entre los sitios Brönsted y Lewis del material [10]. La selectividad hacia el DES (Fig. 5B) también refleja este comportamiento en $\mathrm{ZrO}_{2}$-SBA-15H. La mayor conversión alcanzada en la reacción homogénea con HPA respecto de A36, puede explicarse por la ausencia de efectos difusionales y por la elevada acidez de Brönsted del HPA. Sin embargo, con este catalizador la selectividad hacia el DES es menor que cuando se usa la resina. Por otra parte, el C-3 exhibe valores de conversión semejantes a A36, pero con selectividades superiores hacia el MES. El otro material sintetizado a partir de almidón con una mayor impregnación de ácido p-toluensulfónico (C-7) muestra menores conversiones y selectividades hacia el DES. Por su parte, los carbones activados impregnados con HPA y sin impregnar, tuvieron los desempeños más bajos, resultando mejores aquellos con mayor carga de HPA.
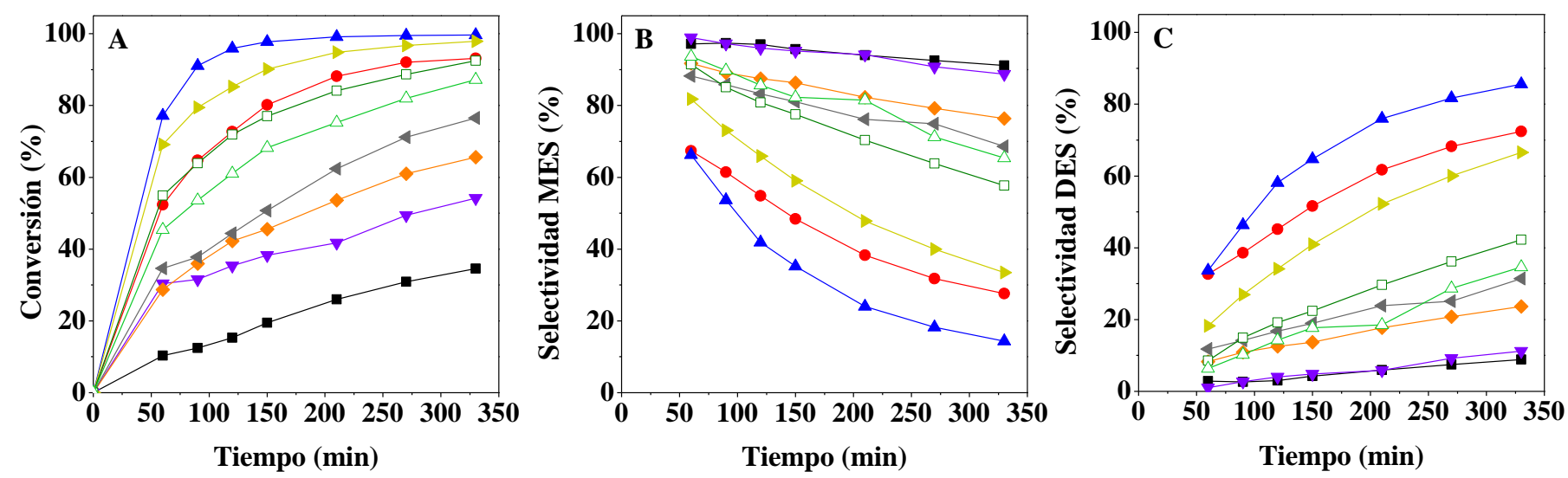

Blanco

A36

$-\mathrm{ZrO}_{2}-\mathrm{SBA}-15-\mathrm{H} \longrightarrow \mathrm{CA}$

HPA/CA- $10 \%$

HPA/CA-20\%

HPA-Homogenea -

C-3 $\triangle \mathrm{C}-7$

Fig. 5. Comportamiento de los catalizadores respecto a las conversiones de AS (A) y selectividades hacia el DES (B) y MES (C). 
Catalizadores como $\mathrm{ZrO}_{2}-\mathrm{SBA}-15-\mathrm{H}$, la resina A36, el heteropoliácido HPA (en reacción homogénea) y el carbón sintetizado C-3, alcanzan conversiones elevadas en un período corto de la reacción. Sin embargo, la selectividad hacia el DES no aumenta en igual medida en todos ellos. Esto último puede notarse en la reacción homogénea de HPA, que pese a tener conversiones elevadas, exhibe selectividades hacia el DES menores que A36 cuya conversión es inferior. Teniendo en cuenta estos resultados y según lo informado en la Tabla 1, podría inferirse que una mayor acidez en el catalizador favorece la conversión de AS, pero que la selectividad hacia el DES se encuentra afectada por otros factores como pudiesen ser la porosidad del material, presencia de sitios Brönsted, Lewis, o determinados grupos funcionales.

\section{Conclusiones}

De lo estudiado hasta el momento pudo comprobarse que la conversión del AS y selectividad hacia el DES en la reacción catalizada con $\mathrm{A} 36$, son sensibles a la temperatura en el rango de 80 a $100^{\circ} \mathrm{C}$ y a la carga de catalizador en el intervalo de 0.5 a 1.0 \%p. Por su parte la velocidad de agitación en el intervalo de 600 a 1000 rpm y la relación molar de los reactivos alimentados de 1:10 a 1:30 no afectan de forma significativa la conversión de AS y selectividad hacia el DES. Los resultados obtenidos con C-3 sintetizado a partir de almidón, muestran que es posible el desarrollo de procesos catalíticos utilizando productos procedentes de la biomasa que favorezcan la producción de compuestos básicos para la elaboración de plastificantes. Este catalizador demostró ser efectivo en la esterificación de ácido succínico con etanol, aunque las selectividades son mayores hacia el monoester. También fue posible el desarrollo de un material ácido no orgánico como la $\mathrm{ZrO}_{2}-\mathrm{SBA}-15-\mathrm{H}$ el cual fue el mejor catalizador probado sobre la reacción con las mejores selectividades hacia el DES. La impregnación de HPA sobre CA resultó poco eficiente y su actividad en reacción fue moderada. La actividad del HPA en la reacción homogénea fue elevada, atribuible a que no existen impedimentos difusionales y a la elevada acidez de tipo Brönsted.

\section{Referencias}

[1] Mersiowsky I., Brandsch R., Ejlertsson J. (2001). Screening for Organotin Compounds in European Landfill Leachates. Journal of Environmental Quality 30(5):1604-11. doi: 10.2134/jeq2001.3051604x.

[2] Ceresana's latest report details growth and change for global plasticizers market. (2019). Recuperado 7 octubre, 2019, de https://www.sciencedirect.com/science/article/pii/S030637471930137X. doi: 10.1016/S03063747(19)30137-X

[3] Pichéa C. D., Sauvageauac D., Vanlian M., Erythropel H. C., Robaireb B., Leaska R. L. (2012). Effects of di-(2ethylhexyl) phthalate and four of its metabolites on steroidogenesis in MA-10 cells. Ecotoxicology and Environmental Safety 79, 108-115. doi: 10.1016/j.ecoenv.2011.12.008.

[4] Erythropel H. C., Dodd P., Leask R. L., Maric M. (2012). Designing green plasticizers: Influence of alkyl chain length on biodegradation and plasticization properties of succinate based plasticizers. Chemosphere 91(3). doi: 10.1016/j.chemosphere.2012.11.061.

[5] Stuart M., Huck W., Genzer J., Müller M., Ober C., Stamm M., Sukhorukov G., Szleifer I., Tsukruk V., Urban M., Winnik F., Zauscher S., Luzinov I., Minko S. (2010). Emerging applications of stimuli-responsive polymer materials. Nature Materials 9 101-113. doi: 10.1038/nmat2614

[6] Budarin, V, Clark JH, Hardy JJ, Luque R, Milkowski K, Tavener SJ, Wilson AJ. (2006). Starbons: new starch-derived mesoporous carbonaceous materials with tunable properties. Angew. Chem. Int. Ed. 2006, 45, 3782 -3786. doi: 10.1002/anie.200600460.

[7] Zuguang L., Song C., Shuo W., Wei Z., Taishun Z., Pengfei L. and Fuhou L. (2015). Activated-Carbon-Supported Phosphotungstic Acid as Novel Heterogeneous Catalysts for Cationic Polymerization of $\beta$-Pinene. Journal of Chemical Engineering of Japan, 48(1), 29-34. doi: 10.1252/jcej.13we330.

[8] Chimienti M. E., Pizzio L. R., Cáceres C. V., and Blanco M. N. (2001). Tungstophosphoric and tungstosilicic acids on carbon as acidic catalysts. Applied Catalysis A: General 208, 7-19. doi: 10.1016/S0926-860X(00)00702-X

[9] Valles V. A., Sa-ngasaeng Y., Martínez M. L., Beltramone A. R. (2019). HDT of the model diesel feed over Ir-modified Zr-SBA-15 catalysts. Fuel 240, 138-152. doi: 10.1016/j.fuel.2018.11.148.

[10] Han X., Du H., Hung C., Liu L., Wu P., Ren D., Huang S. and Liu S. (2015). Syntheses of novel halogen-free BrønstedLewis acidic ionic liquid catalysts and their applications for synthesis of methyl caprylate. Green Chem. 17, 499-508. doi: 10.1039/C4GC01470G. 